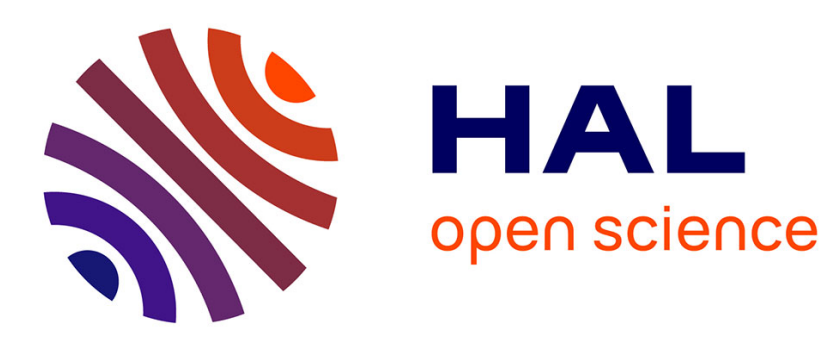

\title{
CVD as Laminar Phenomena with Homogeneous/Heterogeneous Appearances. A Theoretical Analysis
}

\author{
K. Raic
}

\section{- To cite this version:}

K. Raic. CVD as Laminar Phenomena with Homogeneous/Heterogeneous Appearances. A Theoretical Analysis. Journal de Physique IV Proceedings, 1995, 05 (C5), pp.C5-235-C5-242. 10.1051/jphyscol:1995527 . jpa-00253852

\section{HAL Id: jpa-00253852 https://hal.science/jpa-00253852}

Submitted on 1 Jan 1995

HAL is a multi-disciplinary open access archive for the deposit and dissemination of scientific research documents, whether they are published or not. The documents may come from teaching and research institutions in France or abroad, or from public or private research centers.
L'archive ouverte pluridisciplinaire HAL, est destinée au dépôt et à la diffusion de documents scientifiques de niveau recherche, publiés ou non, émanant des établissements d'enseignement et de recherche français ou étrangers, des laboratoires publics ou privés. 


\title{
CVD as Laminar Phenomena with Homogeneous/Heterogeneous Appearances. A Theoretical Analysis
}

\author{
K.T. Raic
}

Faculty of Technology and Metallurgy, Belgrade University, P.O. Box 494, 11001 Belgrade, Yugoslavia

\begin{abstract}
This article presents a general mathematical model for describing the CVD transport phenomena at the geometrically usual substrates: foils (plates) and rotating disks; as well as parallel plates and tube entrances. The model employs an original concept to solve the governing partial differential equations in order to predict the mass transfer at the substrate. Therefore, an approach to the laminar phenomena $[2,3,4]$ established on the simplified form of fundamental partial differential equations is described. On the basis of this equation an integral method is derived. This method is reduced to balance setting of flux gradients (FG-codes) of the transfer phenomena that occur. The present methodology is applied to the laminar phenomena with homogeneous/heterogeneous appearances as appropriate example of CVD simulation.

Interphase mass enhancement caused by homogeneous/heterogeneous appearances, is carefully explained.

Flux gradient and surface diffusion concepts are used to determine the concentration distribution near the interphase. The model can be used as a tool in computer-aided process optimization.
\end{abstract}

\section{INTRODUCTION}

In the published literature on CVD models [1], the common feature of employing a numerical scheme to solve the governing partial differential equations to obtain velocity, temperature and concentration profiles is evident. In this study a general strategy based on laminar boundary layer concept is proposed for modelling the coupled transport phenomena within the CVD reactors.

The complex set of the fundamental partial differential equation of laminar phenomena can be simplified to an ordinary differential equation. Solution of this equation, normalized concentration distribution $\theta$, is considered in the most general sense of term with analogous meaning for momentum, mass, heat, chemical reaction, electro-magnetic forces etc. For example, momentum, as analogous to concentration, by its distribution in the laminar boundary layer, forms a corresponding flux gradient (FG). Accordingly, a heterogeneous appearance can be observed as a phenomenon of concentration change with the corresponding distribution and FG $[2,3,4,5]$.

Typical example of application is a simultaneous mass transport from laminar flow to the surface and diffusion at and/or into solid. Appropriate engineering situation is the CVD simulation. Chosen instances are flow and mass transfer behavior for convective enhancement caused by homogeneous/heterogeneous appearances. Homogeneous appearances are present inside a phase (i.e. pressure gradient, homogeneous chemical reaction, electro-magnetic forces, plasma etc.). Heterogeneous appearances are present on interphase (i.e. condensation, heterogeneous chemical reaction, surface heterogeneities, etching etc.)

For the observed processes, it is assumed that the substrate temperature during the mass transport is constant or slightly variable. 


\section{THEORY}

The general equation (Navier Stokes) is simplified in two directions: steady state flow and unsteady state nonflow. Since appropriate partial diff. eq.s, are mathematically similar, they are substituted by an ordinary diff.eq. $[2,3]$

$$
\mathrm{f}(\mathrm{N}) \xi \mathrm{g}(\mathrm{N})+\Pi \theta^{\prime \prime} \pm \mathrm{f}(\mathrm{m})=0
$$

where: $\xi=y / \delta \chi$ is dimensionless distance from interphase $\epsilon(0,1), \delta \chi$ - boundary layer thickness at position $\quad \chi==\mathrm{f}(\mathrm{m} / \mathrm{m}+1), \quad \Pi$ - relative diffusivity, $\theta^{\prime \prime}=\mathrm{d}^{2} \theta / \mathrm{d} \xi^{2}, \theta=\mathrm{Cx} / \mathrm{Cmax}(\chi)$ - normalized concentration distribution $\in(0,1), C x$ - local concentration at the cross section, $C \max (\chi)-\operatorname{local}$ core concentration at the position $\chi$ and $\mathrm{m}$ - characteristic whole number.

Intraducing the relevant boundary conditions the solution of eq. (1) when $\Pi=1$, becomes the polynomial

$$
\theta=N \xi \pm 0.5 \mathrm{f}(\mathrm{m}) \xi^{2} \pm(\mathrm{N}-1) \xi^{[N / \pm(N-1)]^{( \pm 1)^{*}}}
$$

The criterion $N=d \theta /\left.d \xi\right|_{\xi=0}$ defines the state at the cross-section perpendicular to the surface and enables the comparison and classification of laminar boundary layers within previously defined reference $\left(\theta_{\mathrm{N}=1}=\xi\right.$ - simple Couette flow) and boundary distributions (lower: $\theta_{\mathrm{N}=0}=1$ - free flow and upper: $\theta_{\mathrm{N}=2}=2 \xi-\xi^{2}$ - quadratic Poiseuille flow)

In other words the solutions of eq.(1) are families of polynomial curves grouped in the regions of $\mathrm{N}$ :

$$
[0,1 / 2] \quad[1 / 2,1] \quad[1,3 / 2] \quad[3 / 2,2]
$$

with appropriate sign "+" or "-" as well as $\mathrm{N}$ and $\mathrm{f}(\mathrm{m})$ :

$$
\begin{array}{lcccc}
\mathbf{N}= & 1-\mathbf{m} /(\mathbf{m}+\mathbf{1}) & \mathbf{m} /(\mathbf{m}+1) & 2-\mathbf{m} /(\mathbf{m}+\mathbf{1}) & 1+\mathbf{m} /(\mathbf{m}+\mathbf{1}) \\
\mathbf{f}(\mathbf{m})= & 2-1 / \mathbf{m} & 2-\mathbf{m} & \mathbf{m} & 1 / \mathbf{m}
\end{array}
$$

The term $f(N) \xi \mathfrak{R}(N)$ simulates the partiality of starting equations. The functions $f(N)$ and $f(N)$, for a certain region and chosen criterion $\mathrm{N}$, become constants in the form of whole number or fraction. The function $\mathrm{f}(\mathrm{m})=\mathrm{d} \theta /\left.\mathrm{d} \xi\right|_{\xi=1}$ indicates the homogeneous appearances coupled with variable core velocities $V \max (\chi)$ at characteristic distances along the interphase. This hydrodynamic factor directly participates in the convective mass transport. On the other hand, the volume homogeneity is incorporated into the basic distribution, through the correctly chosen region of criterion $\mathrm{N}$ change. The cross with arrowheads in Figure 1, indicates the direction of $N$ and/or $f(m)$ influence on boundary layer thicknesses $\left(\delta_{v}\right.$ : velocity, $\delta_{c}$ : concentration, $\delta_{H}$ - heterogeneity).

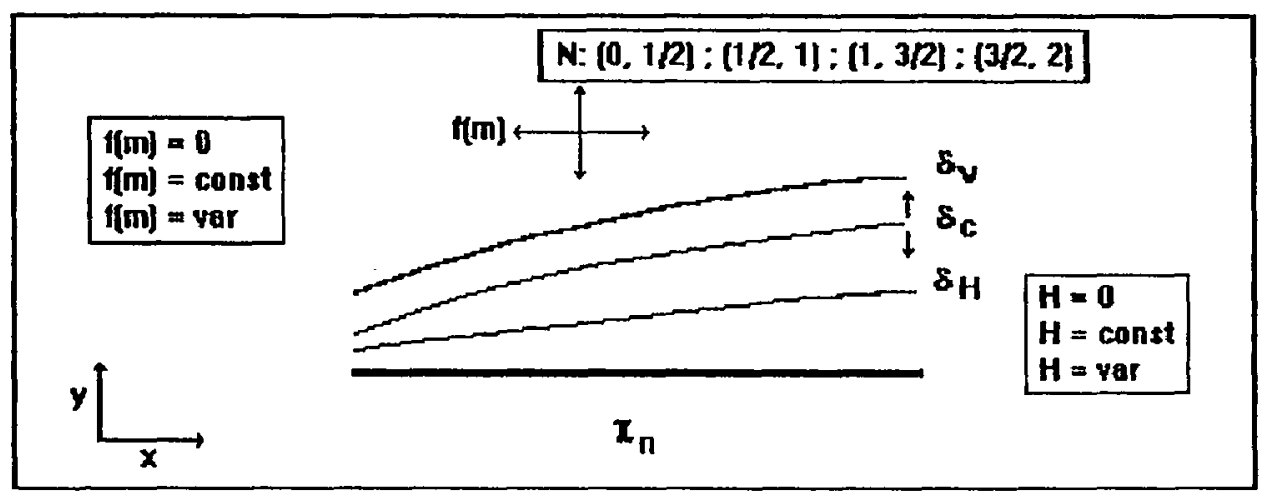

Figure 1: The simulation system of laminar boundary layer at position $\chi_{n}$ 
The heterogeneous appearance $(H)$ that occurred aloug the interface can be observed as a phenomenon of concentration change with the corresponding distribution $\theta$ of region $[0,1 / 2]$ with modified exponents $(*-1)$ as opposite to ordinary laminar distribution $\left.{ }^{*}+1\right)$, see eq.(2). Within borders caused by laminar conditions, heterogeneous appearances are relatively independent. About mass transfer on heterogeneous surface in laminar surround see [4].

The total coupling of the whole system is realized by the quantity $m$, which has a physical meaning of its own. Generally, the $\mathrm{m}$ presents the ratio of formation and decomposition processes. The simulated system is shown in Figure 1.

Exact solution of starting partial diff.eq.s, the "real" concentration distribution (C), has no error. The solution of proposed eq. is an approximate concentration distribution $(\theta)$ in the form of polynomials with changeable coefficients and exponents. The difference $(C-\theta)$ could be surpassed, when necessary, by applying the original modification of Fine Difference Method [6,7]. This method takes into account continuous correction of the diffusivity according to actual concentration (and temperature fluctuation) in laminar boundary layer. Mod.FDM is a "fast" and sensitive numerical method.

\section{MODELLING}

The "simplified" eq. defines the Flux Gradient (FG-code) of the concentration change phenomena at the cross-section perpendicular to the surface

$$
F G=\int_{1}^{0} \theta^{\prime \prime} d \xi=N+f(m) ; N \in(0,2), f(m) \in(0, \pm \infty)
$$

In principle there are laminar layers with: constant $F G$ along the flow $(x-)$ axis $(F G=N ; f(m)=0)$ i.e. the laminar boundary layer over a flat plate or rotating disk and variable FG i.e. laminar entrance region flow, when every position of $\chi$ has its corresponding distribution. Those positions are changeable nodal locations and present the basic grids of second step numerical treatment, Figure 2.

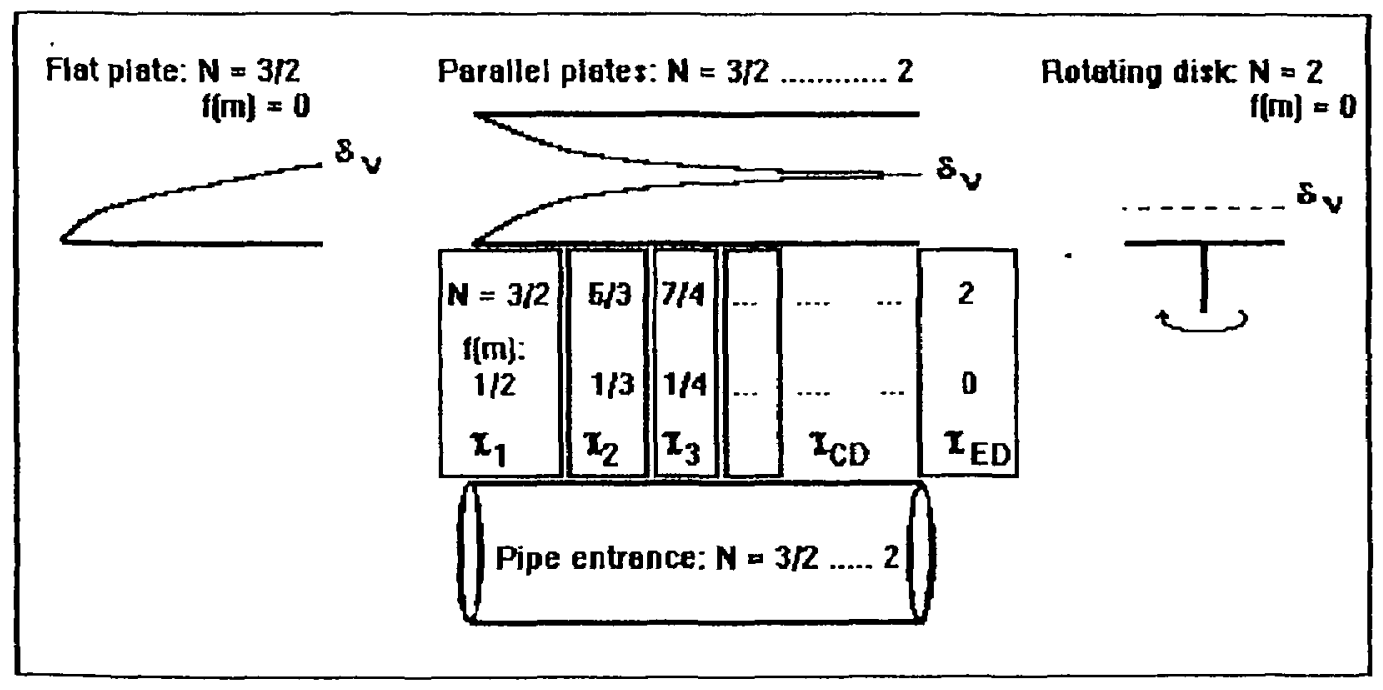

Flgure 2: Schematic description of velocity laminar boundary layers of basic substrate shapes

Mass transfer in a boundary layer can be accompanied by homogeneous/heterogencous appearances. For example, the mass of corresponding concentration diffuses through the fluid toward the substrate simultaneously participating in some homogeneous/heterogeneous appearances. 
The modeling procedure of such a system, therefore, reduce to the constitution of balances of FG. codes of the phenomena occurring within a system. Momentum flow (v) is the "promoter" of the whole mass transport. By its velocity distribution along the interphase it produces a FG-code which induces identical behavior of the diffusion processes (D) in fluid as well as in solid (Ds). Heterogeneous appearances $(\mathrm{H})$ easily embarrasses the mass transport process, so

$$
F G_{v} d x=\left(F G_{D} \pm F G_{H}\right) d x
$$

Solid body surrounded by laminar flow accepts its own FG-code from fluid, or

$$
\left(F G_{D} \pm F G_{H}\right) d x \Rightarrow F G_{D s} d y
$$

According to balance (4), referent situation $\mathrm{N}_{\mathrm{V}} \mathrm{dx}=\mathrm{N}_{\mathrm{D}} \mathrm{dx}$ and simplified analysis of Frank-Kameneskii [7]: $\mathbf{k C o}=\beta(\mathrm{Cmax}-\mathrm{Co})$; where: $\mathrm{k}$ - chemical reaction rate constant, $\beta$ - mass transfer coefficient, $C \max$ and $\mathrm{Co}$ - bulk and surface concentration, the model of mass transfer coefficient is developed

$$
\beta=k(\mathrm{Co} / \mathrm{Cmax}) /(1-\mathrm{Co} / \mathrm{Cmax})\left\{1 / 1-\left[ \pm \mathrm{f}(\mathbf{m})_{\mathrm{v}} \pm \mathrm{f}(\mathbf{m})_{\mathrm{D}} \pm \mathrm{FG}_{\mathrm{H}}\right] / \mathrm{N}_{\mathrm{v}}\right\}
$$

Influence of $f(m)_{v}$ on the dimensionless surface concentration

$$
\mathrm{Co} / \mathrm{Cmax}=1 /\left\{1+\mathrm{z}\left[1-\left( \pm f(\mathrm{~m})_{\mathrm{U}} \pm \mathrm{f}(\mathrm{m})_{\mathrm{D}} \pm \mathrm{FG}_{\mathrm{H}}\right) / \mathrm{N}_{\mathrm{v}}\right]\right\} ; z=\mathrm{k} / \boldsymbol{\beta}
$$

for a first order reaction and balance $\left[\mathrm{N}_{\mathrm{U}} \pm f(\mathrm{~m})_{\mathrm{v}}\right] \mathrm{dx}=\mathrm{N}_{\mathrm{D}} \mathrm{dx}$ is presented on the Figure 3a (regions: $[0,1 / 2]$ and $[1 / 2,1]$ ) and Figure $3 b$ (regions: $[1,3 / 2]$ and $[3 / 2,2]$ ).

Influence of $\mathrm{N}_{\mathrm{H}}$ on the Co/Cmax for a first order reaction and balance $\mathrm{N}_{\mathrm{U}} \mathrm{dx}=\left(\mathrm{N}_{\mathrm{D}} \pm \mathrm{N}_{\mathrm{H}}\right) \mathrm{dx}$ constituted over a heterogeneous surface of foil is presented on the Figure 4 . The connection between $\mathrm{N}_{\mathrm{H}}$ and surface coverage based on HIO model [9] is given on Figure 5. Relative mass transfer coefficient $\left(\beta^{*} / \beta \mathrm{O}\right)$ on the equilibrium temperature, corrected by the appropriate values of $N_{H}$, is shown as a function of the surface coverage $A$. It is assumed that the mass transfer coefficient is analogous to the surface diffusion coefficient $\left(\beta \mathrm{dx}=\mathrm{D}^{\text {surf }}\right)[4]$.

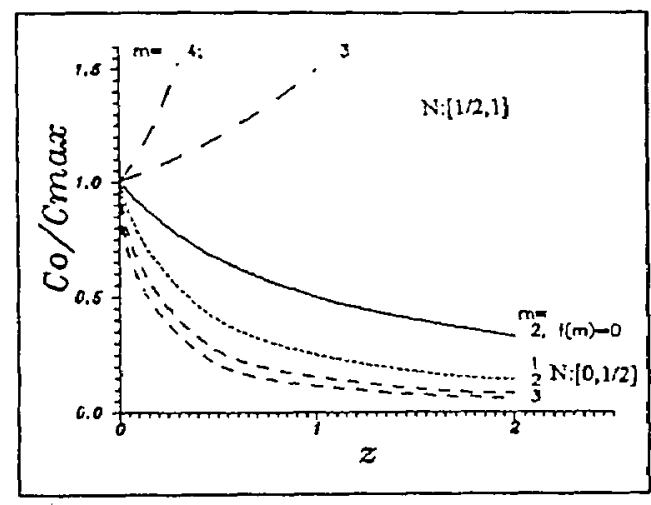

a) regions of $N:[0,1 / 2]$ and $[1 / 2,1]$

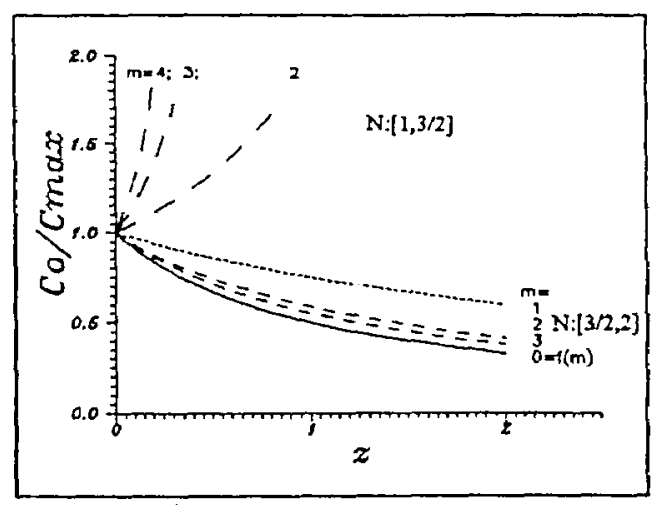

b) regions of $\mathrm{N}:[1,3 / 2]$ and $[3 / 2,2]$

Figure 3: Influence of $f(m)_{U}$ on the Co/Cmax for a first order reaction and balance $\left[N_{U}+f(m)_{U}\right] d x=N_{D} d x$ 


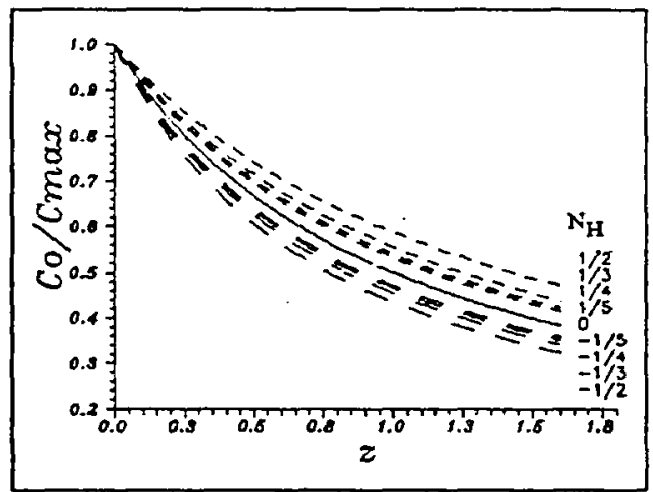

Figure 4: Influence of $\mathrm{N}_{H}$ on the $\mathrm{Co} / \mathrm{Cmax}$ for a first order reaction and balance $\mathrm{N}_{v} \mathrm{dx}=\left(\mathrm{N}_{\mathrm{D}} \pm \mathrm{N}_{\mathrm{H}}\right) \mathrm{dx}$

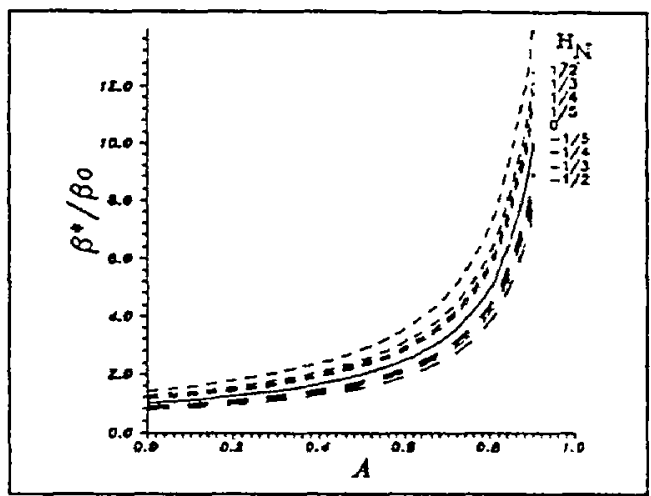

Figure 5: Relative mass transfer coefficient $(\beta * / \beta o)$ vs surface coverage $A$ for various $N_{H}$ $\left(\beta^{*}\right.$ : real and $\beta 0$ : initial mass transfer coefficient [4])

\section{VERIFICATION}

\subsection{Steady state flow}

The modeling procedure is applied to the momentum laminar plienomena: (i) over a flat plate in order to investigate pure deformations of velocity distribution in y-direction [3,5], (ii) between parallel plates in simplified version when $f(m)=0$ [5] and (iii) herein the pipe entrance. Results agree with classic solutions and experimental data.

E.g., the usual physical model, i.e. Shingo, identifies the laminar entrance region flow as the "inlet" and the fully viscous region as the "filled" [10]. In the present approach there is no such rigorous separation of "regions". So, the "inlet" from the critical distance (CD), slowly develops into the "filled". The end distance of this regions (ED) is the beginning of fully developed Poiseulle flow. Throughout the boundary layer development, there exist the characteristic positions $(N, C D$ and ED) of the corresponding distributions, Figure 6 . The first step calculation results of the proposed model are compared to literature data for the case of smooth pipes [10], Figure 7. In this simplified analysis, the evaluation of boundary thickness development is analogous to the changeable part of $\mathrm{N}$ criterion: $\delta_{\mathrm{N}} / \delta_{\mathrm{CD}} \approx \delta_{\mathrm{N}} / \delta_{\mathrm{N}=2} \approx \mathrm{m} /(\mathrm{m}+1)$ with appropriate position $\chi_{\mathrm{N}}$, function of $\mathrm{m} /(\mathrm{m}+1), \chi_{\mathrm{CD}}, V \max (\chi)$. 


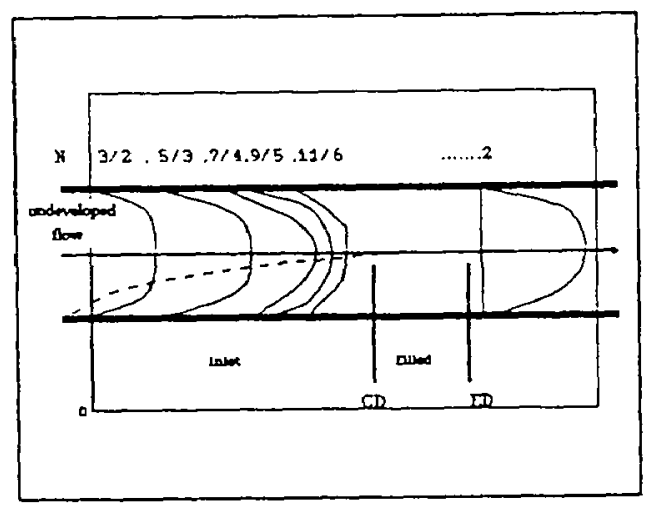

Figure 6: The boundary layer development thickness (pipe or parallel plates entrance)

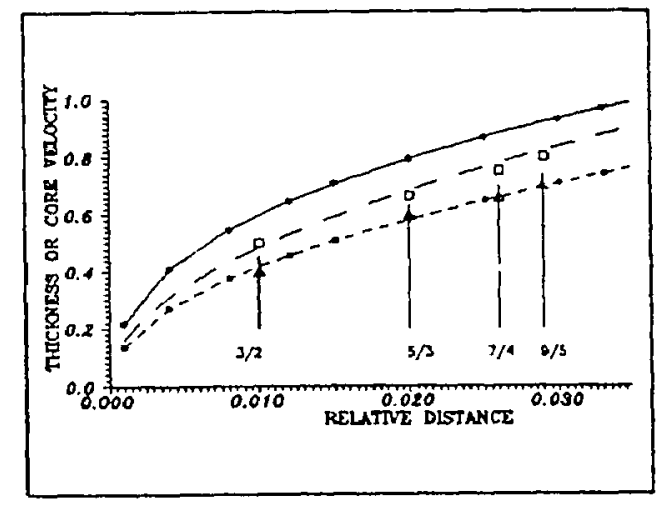

Figure 7: Predicted and experimental values of relative boundary layer $(*-[10], \square$-proposed model) and relative core velocity $(\bullet-[10]$, $\Delta$ - proposed model) vs relative distance ( $x / R R c)$

\subsection{Unsteady state nonflow}

Interpretation of usual unsteady state situations (flow near wall suddenly set in motion as analogous to unsteady state non flow and unsteady flow in a pipe solved by Szymanski [11]) is possible in the sense of proposed model.

So, a theory of laminar phenomena is applied to (i) formation phenomena of reaction layer in metalceramics joints bonded with filler metal [12] and (ii) formation of $\mathrm{Fe}_{2} \mathrm{~B}$ boron layer at carbon and low-alloyed steel surfaces [13]. In both cases the simple model of growth mechanism of reaction layer is presented. It is assumed that the reaction (laminar boundary) layer growth is controlled by diffusion of an arbitrarily chosen element through the layer. The effects of the heterogeneities (i.e. wettness $\mathrm{N}_{W}$ and/or heterogeneous chemical reactions $\mathrm{N}_{h}$ ) on reaction layer growth have been theoretically studied in term of a proposed model. Calculation results are compared with experimental data and usual mathematical procedure when Johnson-Mehl or Austin-Rickett equations were applied.

\subsubsection{Basis of the model}

The model has the same mathematical ground as steady state flow model. The boundary layer approach is used in order to obtain information about the behavior in the neighborhood of the interface. Approximate solutions for the concentration profiles in a thin boundary layer near the interface are recommended. Therefore, the general equation of concentration distribution is adopted to the case of one side unsteady state diffusion in solid which is analogous to flow near a wall suddenly set in motion [11]. The integral method, based on setting mass balances for the control volume, is used. The model considers the boundary layer development as a function of time. The following assumptions are made: (1) at any time $t$, there is a boundary-layer thickness $\delta(t)$ beyond which there is no diffusion, so the concentration change is confined to the region $0 \leq \zeta \leq 1(\zeta=y / \delta(t))$ and $(2)$ the dimensionless concentration profiles, $\theta$

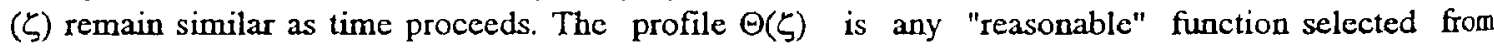
data in $[3,5,12]$. We can develop the expression for $\delta(t)$ in terms of any function $\Theta(\zeta)$ taking the values for $N$ and $M$ from data in $[3,5,12]$. Generally, the boundary layer thickness increases as square root of the time. The total heterogeneity $\mathrm{N}_{\mathrm{H}}=\mathrm{NW}_{W}+\mathrm{N}_{\mathrm{h}}+\ldots$ participates in the mass transpor process and is evident after some time $t^{*}$. So, at time $t^{*}$ one obtains (see Figure8) where:

$M={ }_{0}^{j} \Theta \mathrm{D}^{\mathrm{d} \zeta}$ - the total concentration amount, $\mathrm{D}-$ the diffusion coefficient throughout the reaction layes, 


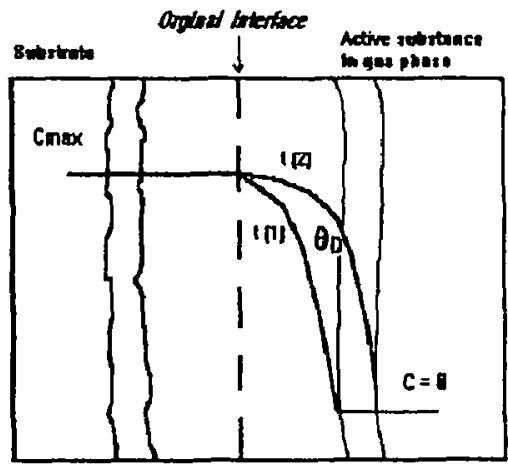

\section{Stage (1): $t(1)<t(2)<t^{*} ; N_{H}=0$}

Mass balance: $M \delta d \delta=D N_{D} d t$. Integration gives: $\delta(t)_{I}=\left[\left(2 N_{D} D / M\right) t\right]^{1 / 2}+$ const, or $\delta(t) I=a_{I} t^{1 / 2}+b_{I}$

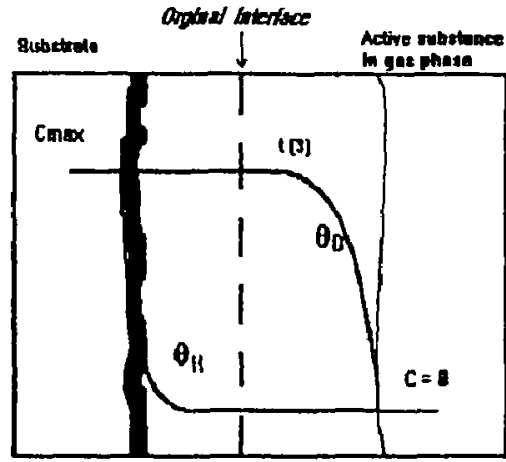

\section{Stage (II): $t[\mathbf{l}]>t^{*} ; \mathbf{N}_{H}>0$}

At time $t^{*}: M \delta d \delta=D\left(N_{D}+N_{H}\right) d t$. Integration gives: $\delta(t)_{\Pi}=\left\{\left[2\left(N_{D}+N_{H}\right) D / M\right] t\right\} 1 / 2+$ const or $\delta(t)_{\Pi}=a_{I} t^{1 / 2}+b_{I I}$. Also, in "critical time" $t^{*}$ at "critical thickness " $\delta^{*}$ one obtains the ratio: $N_{H^{\prime}} N_{D}=$ $=1-\left(a_{I I} / a_{I}\right)^{2}$ that indicates the "power" of total heterogeneity.

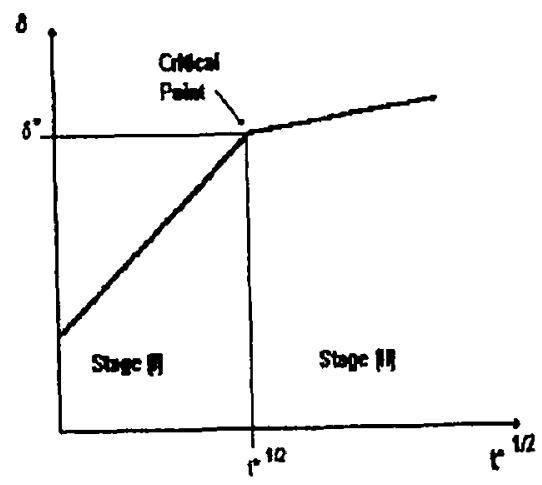

Figure 8. Schematic illustration of unsteady state nonflow model

Stage(I): When the heterogeneity does not occur (or is negligible), $t<t^{*}$

Stage(ii): When the heterogeneity does occur, $t>t^{*}$ 
$N_{D}=\left.\Theta_{D}^{\prime}\right|_{0}{ }^{1}$ - the diffusion flux, $N_{H}=\left.\Theta_{H}^{\prime}\right|_{0}{ }^{1}$ - the total heterogeneity flux

$\Theta_{D}=\left(1-\theta_{D}\right)$ - dimensionless concentration ratio of diffusion, $\theta_{D}[3,5,12]$ and

$\Theta_{H}=\left(1-\theta_{H}\right)$ - dimensionless concentration ratio of total heterogeneity, $\theta_{H}[3,5,12]$.

\subsection{On analogous processes}

Also, the laminar boundary concept is applied to the phenomena on the metal surface; mass transport during a homogeneous/heterogeneous chemical reaction in the laminar layer over measuring foil of conventional gas carburizing process. A model of mass transfer coefficient, eq. (6), is presented as a function of the limiting heterogeneous chemical reaction rate constant, characteristic time relation and surface function of the appropriate furnace atmosphere. So, the calculated value of chemical rate constant is corrected by two parameters. The firs one, obtained by measuring the characteristic times, indicates to what extend the furnace atmosphere is "equilibrated". The second one, obtained by measuring the characteristic surface coverage, indicates the mechanism of the heterogeneous chemical reaction $[3,14]$.

\section{CONCLUSION}

The presented approach is imagined as a flexible iterative system. It is shown in the simplified form for the sake of clarity. Only the essential instructions of simulation procedure are given. In order to solve the real situation, it is necessary to determine the following: (i) the interval/range of $\mathrm{N}$ criterion change, (ii) the deformation of the concentration distribution in the $y$-direction caused by the heterogeneous appearances and (iii) the action of the $\mathrm{f}(\mathrm{m})$ or homogeneous appearances. It is emphasized that the model should be tested with more experimental results. A greater efficiency of the method is expected by improving the calculation procedure according to experimental data. In second step, the standard numerical methods (Spectral, Finite elemente or Finite difference) may be used.

\section{References}

[1] Jensen K.F., Chem.Eng.Sci, 42(1987) 923.

[2] Raic K.T., Laminar phenomena during homogeneous/heterogeneous appearances, 1994, unpublished

[3] Raic K.T., ISIJ Int., 32(1992) 514.

[4] Raic K.T., ISUJ Int., 33(1993) 1281.

[5] Raic K.T. et al., J.Serb.Chem. Soc. 57(1992) 287.

[6] Raic K.T. and Popovic Z.V., J.Heat.Treat., 8(1990) 71.

[7] Raic K.T., Scand. J. Metall. (1994) accepted.

[8] Frank-Kamenetskii D.A., Diffusion and Heat Exchange in Chemical Kinetics, Princeton University Press, Princeton, (1960)

[9] Higashi K., Ito H. and Oishi J., J.Atomic Energy Soc.Japan, 5(1963) 846.

[10] Mohanty A.K. and Asthana S.B.L., J.Fluid.Mech., 90(1978) 433.

[11] Bird R.B, Stewart W.E. and Lightfoot E.D., Transport Phenomena, John Wiley and Sons, NewYork, (1960)

[12] Raic K.T. et al., "Modelling of reaction layer growth in metal-ceramic joints bonded with filler metal", 8th Cimtec, Florence, june 28 - july 4, 1994, paper B9: P23, Proceedings in press

[13] Raic K.T. et al., J.Serb.Chem. Soc. (1995) submitted.

[14] Raic K.T., Zastita materijala/Materials protection, 3(1994) 105. 